\title{
Scientific Media dieting and Students Awareness and Expectations about the Environmental Issues of Deforestation and Species Extinction in the Middle East and North America: An Integrated cross cultural Ecologic-Economic Analysis
}

\author{
Ibrahim Niankara \\ College of Business, Al Ain University of Science and Technology, P.O. Box: 112612, Abu Dhabi, UAE; Tel: \\ +97124444696 Ext: 539 ; Fax: +97124444304 ; E-mail: ibrahim.niankara@aau.ac.ae
}

\begin{abstract}
This study inscribes itself in the global discussion about the issue of environmental awareness, beliefs and behaviors. Here we focus on the role that cultural differences and scientific media dieting play in explaining heterogeneities in students' awareness and expectations about the two environmental issues of deforestation and species (plant and animal) extinction in the Middle East and North America. To this end, we use the cross-sectional survey data of the OECD's Program for International Student Assessment (PISA) 2015, along with seemingly unrelated Bi-variate ordered Probit modeling techniques.

The results show that compared to their North American Counterparts, students' in the Middle East are $14.2 \%$ less aware of, and $14.5 \%$ less optimistic about the issue of deforestation, while $38.9 \%$ less aware of, and $59.0 \%$ less optimistic about the issue of species extinction. In addition, we found that science club attendance and broad science reading in books are the two most effective communication media for raising students awareness about the two environmental issues. In fact, every one level increase in students' awareness is found to raise their optimism by $20.4 \%$ for the issue of deforestation, and $15.0 \%$ for the issue of plant and animal extinction. Therefore raising young people environmental awareness and optimism through proper communication strategies, could be invaluable for achieving an economic development in line with our need to preserve the natural environment and ecosystem services for generations to come.
\end{abstract}

Keywords: Deforestation, Environmental Awareness, Media Consumption, Sustainable Development, Species Extinction

JEL: D83, D84, O13, P51, P52, Q5 


\section{Introduction}

On Tuesday March 20 2018, the world woke up to the news of the death of its last male northern white rhino "Sudan" who lived in the Ol Pejeta conservancy in Kenya. The 45 year old animal was put down after the pain from a degenerative illness became too great, leaving behind two females-his daughter and granddaughter - through which conservationists hope to save the species from dying out altogether, using advanced cellular technologies and In Vitro Fertilisation (IVF). Ted Benton, an environmental social scientist at the university of Essex, and member of the Red-Green study group said:

"The fact that this is in the news suggests there is a wider cultural feeling of regret and care about this from so many people who have never seen - and probably never expect to see - a white rhino, and that is heartening in that it shows that people care ... however, the death is part of a much wider and deeper issue - the huge loss of other species ... through the current economic system and globalization we are taking up more of the earth's resources and living space than it can accommodate. This is not just a threat to other species this is a threat directly to our survival as humans too." (The Guardian, 2018).

There is a growing concern for the current and emerging quality of the natural environment (Esra, 2010; Oweini and Houri, 2006; Tekin and Gunes, 2018). These concerns are manifested in expressed anxieties regarding current and future life-styles, quality of life, and economic prosperity on earth (Coertjens et al., 2010; Bozoglu et al., 2016); and are a consequence of how contemporary society is structured, for as multiple organizations pursue their self-interests, the interstices of society become an increasingly degraded residual(Ferraro et al., 2005). Indeed many of the environmental issues observed today are rooted in maladaptive human behavior(Bradley et al., 1999; Ostrom et al., 2002), and therefore can be greatly influenced by raising individual's environmental awareness (Ramsey and Rickson, 1976; Sengupta et al., 2010; Le Hebel et al., 2014).

Numerous authors have studied young people's awareness and overall attitudes towards the environment, as ways of helping to improve the overall behavior of future citizens toward the environment(Bradley et al., 1999; Oweini and Houri, 2006; Coertjens et al., 2010; Esra, 2010; Sengupta et al., 2010; Le Hebel et al., 2014; Bozoglu et al., 2016). Young people awareness and attitudes are particularly important because as future consumers, voters, scientists, and policy makers, they will be directly affected by, and will need to provide solutions to the rising environmental challenges from present-day actions (Sengupta et al., 2010). Although several factors including knowledge about the environment (Arcury, 1990), socio-demographic variables (Esra, 2010), science abilities (Coertjens et al., 2010), student field of interest, and parental educational status (Tekin and Gunes, 2018) are all found to affect young people's awareness and attitudes towards the environment, little is still known about the role that culture and general scientific media dieting play in explaining young people's environmental attitude and behavior. 
Furthermore, looking at the Program for International Student Assessment (PISA) 1 -based test implementation for schools in the USA, Rutkowski (2015) concluded that it can operate as a governance tool, allowing international organizations to have greater influence in the formation and implementation of local educational policies. Similarly, In exploring sub-national PISA participation in Canada and the USA, asking "how" PISA is being used within sub-national education policy spaces, Engel and Frizzell (2015) argue that competitive comparison in education has deepened through the enhanced granularity of international large-scale assessment data to new scales beyond the nation-state. Therefore, In the current paper we take this comparison one step further to understand the regional heterogeneities in young people environmental attitudes, linked to differences in culture and media diet. We achieve this by comparing students environmental attitudes (Awareness and Expectations) in north America (USA and Canada) to their counterparts in the Middle East (UAE and Qatar) with regards to the two issues of deforestation and species (plant and animal) extinction, using data from the PISA 2015. To this end, we raise the following general questions:

- To what extinct are cultural differences between the Middle East and north America materialized in students attitudes about major environmental issues?

- What circumstances and communication strategies give science an effective voice in individuals' and groups decision making regarding environmental issues in the two regions ?

More specifically

- Q01: What effect does students' scientific media diet have on their awareness and expectations about the two environmental issues of deforestation and species (plant and animal) extinction in the Middle East (UAE and Qatar) and North America (USA and Canada)?

- Q02: Are there significant regional heterogeneities in students' awareness and expectations about these two environmental issues between the Middle East and North America?

To the best of our knowledge, these two questions have not yet been specifically addressed in the scientific discourse, therefore in our quest to fill in this gap, we organize the rest of the article as follows; section 02 presents a background discussion on the issues of deforestation and species extinction, and the potential of media diet in raising environmental awareness and optimism; section 03 presents the methods used to answer the questions, by first describing the data, then the variables used in the analysis, and ending with the econometric model; section 04 presents the results, while section 05 discusses their implications, and concludes the analysis.

\footnotetext{
${ }^{1} \mathrm{PISA}$ is a triennial data collection program lunched by the Organization for Economic Co-operation and Development (OECD), on 15 year old students worldwide. See http://www.oecd.org/pisa/ for more general information
} 


\section{Background}

\subsection{Deforestation and Species Extinction}

Contemporary societies are faced with numerous anthropogenic environmental problems among which are the issues of deforestation (Houghton and Nassikas, 2018) and species extinction (Ceballos et al., 2017). The loss of biodiversity that comes with forest clearing is indeed one of the most critical current environmental problems, threatening valuable ecosystem services and human well-being(Ceballos et al., 2010; Barnosky et al., 2011; Mace et al., 2012; McCauley et al., 2015; Ripple et al., 2015; Young et al., 2016; Maxwell et al., 2016). In fact, forests play a critical role in the ecosystem, from providing a natural habitat for both plant and animal species, to removing around 30\% of human-produced carbon dioxide emissions from the atmosphere (Budget, 2016; Field and Mach, 2017), they regulate global temperature(Bright et al., 2017). For these reasons, forest clearing leads to loss of natural habitat and ecosystem services (Dawson et al., 2011), but also threatens plant and animal survival (Ramsfield et al., 2016), often pushing them to extinction (Ceballos et al., 2015). In 2007 the intergovernmental Panel on Climate Change (IPCC) estimated that $20-30 \%$ of the world's species are likely to be at increasingly high risk of extinction from anthropogenic climate change impacts within this century if global mean temperatures exceeds 2-3 degrees Celsius above pre-industrial levels (Fischlin et al., 2007). 10 years later, an estimated 42\% of 3,623 terrestrial invertebrate species, and 25\% of 1,306 species of marine invertebrates assessed on the International Union for Conservation of Nature (IUCN) Red List are classified as threatened with extinction. To characterize the magnitude of this ongoing extinction crises, which authors now describe as a "biological annihilation", Ceballos et al. (2017) use a sample of 27,600 vertebrate species, and a detailed analysis documenting the population extinctions between 1990 and 2015 in 177 mammal species, and conclude that rapidly decreasing population sizes and shrinking ranges amount to a massive anthropogenic erosion of biodiversity and ecosystem services essential to civilization. Observing these devastating consequences of anthropocentric welfarism ${ }^{2}$, researchers are now advocating alternatives to this standard welfare economics assumption, towards one that takes into account the welfare of other species (Eichner and Pethig, 2006), including animal welfare (Frank, 2008; Johansson-Stenman, 2018). This importance is further reiterated in the scientific community through the establishment of animal welfare as a scientific discipline with established journals such as the Journal of Applied Animal Welfare Science, [see for example Coelho et al. (2016)]. One of the latest and pioneering study in economics that directly attempts to measure people's ethical preferences with respect to the weight that animal welfare should have in public decision-making (Johansson-Stenman, 2018) shows that the conventional anthropocentric assumption is problematic, especially when social decision rules are based on people's ethical preferences.

\footnotetext{
${ }^{2}$ The fundamental belief that only human well-being counts intrinsically
} 
Furthermore, Kenter, Bryce, Christie, Cooper, Hockley, Irvine, Fazey, O'Brien, Orchard-Webb, Ravenscroft et al. (2016) show that valuation that focuses only on individual values evades the substantial collective and inter-subjective meanings, significance and value from ecosystems, therefore environmental valuation should be developed into a more pluralistic, comprehensive, robust, legitimate and effective way of safeguarding ecosystems and their services for the future. The ethical, moral and justice dimensions of many environmental issues necessitate approaches that allow for the recognition and elicitation of shared ${ }^{3}$, plural and cultural values Ives and Kendal, 2014; Irvine et al., 2016, Edwards et al., 2016); Which are a better reflection of welfare implications than non-deliberated individual values that rely on the traditional anthropocentric view of welfare (Kenter, Jobstvogt, Watson, Irvine, Christie and Bryce, 2016).

\subsection{Media Diet}

Media diet in general, and scientific media diet in particular represents the sum of scientific information consumed by an individual or a group of individuals (Pozzali and Ferri, 2012). Overall media consumption has evolved in nature and volume over time, following the evolution of communication and information technology (Afifi et al., 2018). With many using different types of social media daily (Kilian et al., 2012), media consumption is having an important grasp on young people today (Boczkowski et al., 2018), and includes activities such as interacting with new media, reading books and magazines, watching television, listening to radio, and surfing the internet Lomborg and Mortensen, 2017). As a useful tool for socializing the younger generations from across the globe (Berger, 2018), mass media also contributes to propagating various social norms (Beaudoin, 2014; Bergström and Jervelycke Belfrage, 2018).

Cultural differences often work to define media consumption patterns in different regions of the world (Gunawan, 2017; Fuller, 2018), and thereby affecting differently individuals' awareness and attitudes towards anthropogenic issues, including those linked to the natural environment. For example, Middle eastern countries such as the United Arab Emirates(UAE) and Qatar differ culturally from their North American counterparts of United States of America (USA) and Canada, on several ground including social, religious, and political (Spykman, 2017). At the social level, North Americans hold an independent construal of the self, therefore facilitating the expansion of competition, incentives and self-interested behavior. In the Middle East however, people hold an inter-dependent construal of the self, with the boundaries between different persons fluctuating across situations and time, making the idea of self-interest a bit antagonistic with the local

\footnotetext{
${ }^{3}$ Shared values are values that relate to a sense of importance transcending individual utility, and that express the multi-dimensionality of values. They are formed, expressed and assigned through social interactions, and convey conceptions of the common good between people.(Kenter et al. 2015) The shared values approaches to valuing ecosystem services can be defined as an approach that recognizes a plurality of values (ontological, ethical, epistemological) that are socially formed, both substantively and procedurally.(Kenter, 2016)
} 
culture( Ferraro et al., 2005).

On the religious front, Middle Eastern countries follow Islamic principles, while North American countries follow predominantly Christian principles. On the Political ground, Middle Eastern countries are more Monarchic, while North American countries are more Democratic. These cultural differences are reflected in differences in local laws and regulations in countries from the two regions (Vieweg and Hodges, 2016), and affect individuals' access to, and consumption of media (Wiest and Eltantawy, 2012; Abokhodair et al., 2017), and thus awareness in general, and environmental awareness and attitude in particular.

One of the latest comprehensive report on media consumption in the Middle East including (UAE, Qatar) (Dennis and Wood, 2017) shows as of 2017 that smart-phones are more common in the Arab world than the USA, with the greatest penetration in the UAE at 99\%, followed by Qatar at 95\%, while the US seats at 77\%. Also 98\% of UAE nationals report getting their news on their smart-phone, compared to $67 \%$ in Qatar. Overall TV news viewership in the region declined by $23 \%$ since 2013, while news-viewing online increased by $41 \%$. Furthermore, $79 \%$ of people reported getting their news and information on social media, with $66 \%$ doing so daily. In addition, $70 \%$ reported social media as an important source for news and information, however fewer than half (47\%) trust the information they get on social media. More over, looking at media bias and credibility among people in the Middle East, the study found that Arab nationals are twice as likely $(66 \%)$ as Americans $(32 \%)$ to say they have trust and confidence in mass media. Although, Arab nationals are less likely to trust the media from other Arab countries (52\%) or the western world (49\%) than the media in their own country $(66 \%)$. On the perception of news coverage by international news organizations, 33\% of Arab nationals believe the news are biased against the Arab world, however this view is even stronger among US nationals at $43 \%$. UAE nationals have more confidence on their local media, with $85 \%$ finding it credible, against $62 \%$ for Qatari nationals.

Given the potential of media consumption to raise public awareness in the two regions Al-Badi, 2014; Abbar et al., 2016), it becomes crucial to get a clear picture of its significance in reducing the anthropogenic environmental issues of deforestation and species extinction(Butler et al., 2018), and thereby shape our future in the direction of sustainable growth and prosperity for all.

\section{Methods}

\subsection{Data and Variables Description}

The data used in this analysis comes from the student questionnaire file of the Programme for International Student assessment (PISA) 2015 (OECD, 2016). PISA is the triennial survey of 15-year-old students around the world lunched by the Organization for Economic Co-operation and Development (OECD), to assess the extent to which the students near the end of their compulsory education, have acquired key knowledge and skills essential for full participation in modern 
societies. Our analysis is based on the 2015 publicly released student questionnaire data file, which includes estimates of student performance and parent-questionnaire data from the 35 OECD countries and 37 partner countries, for a total sample size of 519334 observations. After data treatment, variables selection, and accounting for missing information, our final analysis is based on a total of 25557 students from four countries, divided into two major cultural heritages (regions). In fact, to address the raised questions, the final sample only includes data on students from the middle east (UAE, and Qatar) and North America (USA, and Canada). Table (1) provides definitions and summary statistics for all the explanatory variables used in the analysis. For a detailed description of the 2015 PISA sampling design see the report(OECD, 2017, 67-91).

\subsubsection{Dependents Variables}

The dependent variables in this analysis are represented by students' self-expressed levels of awareness and expectations about the two environmental issues of deforestation and species (plant and animal) extinction.

- Self-Expressed-Awareness (SEA): Is an ordered multinomial variable taking the values (1Never heard, 2-Heard but can't explain, 3-Know and can provide general explanation 4Familiar and can provide detail explanation) for each environmental issue

1. deforestation: $\mathrm{SEAD}$; with mean value $=3.17$, and standard deviation $=0.90$

2. species extinction: SEASE; with mean value $=3.25$, and standard deviation $=0.84$

- Self-Expressed-Expectation (SEE): Is also an ordered multinomial variable taking the values (1-worse, 2-same, 3-Improve) for each environmental issue

1. deforestation: SEED; with mean value $=2.36$, and standard deviation $=0.81$

2. species extinction: SEESE; with mean value $=2.32$, and standard deviation $=0.79$

\subsubsection{Independent variables-Media Diet}

In our analysis, we consider seven medium of communication with summary statistics provided in table (1), which can be grouped into four different types of media (face-to-face, print media, television, the Internet). Each media type involves both content, and an object through which that content is delivered.

- Face-to-face: As the oldest of all, it relates to any type of verbal or non-verbal communication where the sender and the receiver of the information are in the same physical location. It allows the sender to adjust the delivery of the message as needed for more effectiveness, through immediate feedback from the receiver. In our study face-to-face scientific media consumption is captured by students' frequency of science club attendance (ScClubAttend). 
- Print media: is used to describe the traditional or "old-fashioned" print-based media that most of today's parents grew up with, including books, magazines and newspapers. In our current analysis, print media consumption is captured by the frequency with which students read books on broad science topics (BroadScBooks), magazines and science articles in newspapers (MagScArtNewsp).

- Television: Television has been a powerful media for entertaining families for several decades now. In the beginning, there were few programs to pick from, but today, consumers have literally hundreds of general and specialty (including science) channels and programs to choose from. In our study television consumption is captured by student's frequency of television program watching on broad science (BroadScTVprog).

- The Internet: The Internet is a communication technology based on millions of interconnected computers capable of sharing data instantly. All Internet communications, whether voice, video, or photograph, take place using a common digital transmission format. Early websites were largely textual in nature, but have overtime evolved into platforms capable of organizing and displaying all the other forms of media discussed above, including books, magazines, articles, television programs, telephone and textual communications, audio and video recordings. In our current study, internet consumption is captured by (i) the frequency of visits to ecological websites (EcoWebVisit), (ii) the frequency of news blogs following (BlogsVisit), and (iii) the frequency of websites visits on broad science (BroadScWeb).

\subsection{Econometric Model Specification}

Our Bivariate Ordered Probit Model of Awareness and Expectation is derived from the latent variable framework following (Sajaia, 2008). For this we assume that students' latent awareness $\left(A^{*}\right)$ and Expectation $\left(E^{*}\right)$ are determined by the following two equations:

$$
\begin{aligned}
& A_{i}^{*}=X^{\prime}{ }_{1 i} \beta_{1}+\epsilon_{1 i} \\
& E_{i}^{*}=X^{\prime}{ }_{2 i} \beta_{2}+\gamma A_{i}^{*}+\epsilon_{2 i}
\end{aligned}
$$

Where $\beta_{1}$ and $\beta_{2}$ are vectors of unknown parameters, $\gamma$ is an unknown scalar, $\epsilon_{1 i}$ and $\epsilon_{2 i}$ are the error terms, and $i$ denotes the individual student subscript. The explanatory variables in the model are assumed exogenous such that $E\left(X^{\prime}{ }_{1 i} \epsilon_{1 i}\right)=E\left(X_{2 i}^{\prime} \epsilon_{2 i}\right)=0$.

The observed variables for individual's self-expressed awareness $(S E A)$ and self-expressed Expectation $(S A E)$ are related to the corresponding latent variables as: 


$$
S E A_{i}= \begin{cases}1-\text { Never Heard } & \text { if } A_{i}^{*} \leq \mu_{1} \\ 2-\text { Heard, but Unable to Explain } & \text { if } \mu_{1} \leq A_{i}^{*} \leq \mu_{2} \\ 3-\text { Know, can provide General Explanation } & \text { if } \mu_{2} \leq A_{i}^{*} \leq \mu_{3} \\ 4-\text { Familiar, can provide Detailed Explanation } & \text { if } \mu_{3}<A_{i}^{*}\end{cases}
$$

$$
S A E_{i}= \begin{cases}1-\text { Worse } & \text { if } E_{i}^{*} \leq \delta_{1} \\ 2-\text { Same } & \text { if } \delta_{1} \leq E_{i}^{*} \leq \delta_{2} \\ 3-\text { Improve } & \text { if } \delta_{2}<E_{i}^{*}\end{cases}
$$

Where the unknown cutoffs satisfy the condition that $\mu_{1}<\mu_{2}<\mu_{3}$ and $\delta_{1}<\delta_{2}$. For identification purposes, the first threshold values are "anchored" a priori, such that $\mu_{1}=\delta_{1}=0$. Following Jackman, 2000, McKelvey and Zavoina, 1975), we also define $\mu_{0}=\delta_{0}=-\infty$ and $\mu_{4}=\delta_{3}=+\infty$ in order to avoid handling the boundary cases separately.

The probability that $S E A_{i}=j$ and $S A E_{i}=k$ is:

$$
\begin{aligned}
\operatorname{Pr}\left(S E A_{i}=j, S A E_{i}=k\right) & =\operatorname{Pr}\left(\mu_{j-1}<A_{i}^{*} \leq \mu_{j}, \delta_{k-1}<E_{i}^{*} \leq \delta_{k}\right) \\
& =\operatorname{Pr}\left(A_{i}^{*} \leq \mu_{j}, E_{i}^{*} \leq \delta_{k}\right) \\
& -\operatorname{Pr}\left(A_{i}^{*} \leq \mu_{j-1}, E_{i}^{*} \leq \delta_{k}\right) \\
& -\operatorname{Pr}\left(A_{i}^{*} \leq \mu_{j}, E_{i}^{*} \leq \delta_{k-1}\right) \\
& +\operatorname{Pr}\left(A_{i}^{*} \leq \mu_{j-1}, E_{i}^{*} \leq \delta_{k-1}\right)
\end{aligned}
$$

If $\epsilon_{1 i}$ and $\epsilon_{2 i}$ are distributed as bivariate standard normal with correlation $\rho$ the individual contribution to the likelihood function could be expressed as:

$$
\begin{aligned}
\operatorname{Pr}\left(S E A_{i}=j, S A E_{i}=k\right) & =\Phi_{2}\left(\mu_{j}-X^{\prime}{ }_{1 i} \beta_{1},\left(\delta_{k}-\gamma X^{\prime}{ }_{1 i} \beta_{1}-X^{\prime}{ }_{2 i} \beta_{2}\right) \zeta, \tilde{\rho}\right) \\
& -\Phi_{2}\left(\mu_{j-1}-X^{\prime}{ }_{1 i} \beta_{1},\left(\delta_{k}-\gamma X^{\prime}{ }_{1 i} \beta_{1}-X^{\prime}{ }_{2 i} \beta_{2}\right) \zeta, \tilde{\rho}\right) \\
& -\Phi_{2}\left(\mu_{j}-X^{\prime}{ }_{1 i} \beta_{1},\left(\delta_{k-1}-\gamma X^{\prime}{ }_{1 i} \beta_{1}-X^{\prime}{ }_{2 i} \beta_{2}\right) \zeta, \tilde{\rho}\right) \\
& +\Phi_{2}\left(\mu_{j-1}-X^{\prime}{ }_{1 i} \beta_{1},\left(\delta_{k-1}-\gamma X^{\prime}{ }_{1 i} \beta_{1}-X^{\prime}{ }_{2 i} \beta_{2}\right) \zeta, \tilde{\rho}\right)
\end{aligned}
$$

where $\Phi_{2}$ is the bivariate standard normal cumulative distribution function, $\zeta=\frac{1}{\sqrt{1+2 \gamma \rho+\gamma^{2}}}$ and $\tilde{\rho}=\zeta(\gamma+\rho)$. This specification is referred to as simultaneous bivariate ordered probit model. When $\rho=0$ then the model simplifies to a seemingly unrelated specification with $\zeta=1$ and $\tilde{\rho}=\rho$. The closed form solutions of the likelihood function are described in details in the appendix. The model is estimated here under seemingly unrelated specification $(\rho=0)$, using the package Sarrias (2016) from the $\mathrm{R}$ statistical software( $\mathrm{R}$ Core Team, 2015). 


\section{Results}

The results are structured in two parts, the descriptive results discussed next in section (4.1), and the econometric results discussed in section (4.2).

\subsection{Descriptive Results}

The descriptive results are broken down into four parts and presented in the sub-sections (4.1.1) (4.1.2) 4.1.3) and 4.1.4 ) below. We first present in sub-section 4.1.1 the summary statistics shown in table (1), followed by a presentation of the absolute frequency distributions of awareness and expectations about the two environmental issues of deforestation and species extinction in subsections (4.1.2), then by that of the conditional frequency distribution by region in sub-sections 4.1.3, and finally by the conditional frequency distribution by country in sub-sections 4.1.4.

\subsubsection{Summary Statistics of the Explanatory variables}

As shown in table (1), the descriptive results suggest that $46 \%$ of the students respondent are males, with an average student age of 15.80 years. The mean value of the standard normalized scale of the index of economic, social and cultural status (ESCS) 4 , suggests that the average student in our studied sample is 0.56 standard deviation above the mean index value across all PISA 2015 students. The mean value of 0.46 for the binary regional variable "MENA" suggests that nearly half of the students (46\%) come from the middle east, and the remaining $54 \%$ from North America. In addition, the average student is interested (3.41) in the biosphere (ecosystem services and sustainability), but highly interested (3.99) in how science can help prevent disease.

Furthermore, table (1) shows that on average students mean media consumption is around 3, with a standard deviation of about 0.90. This suggest that the average student regularly consume each of the media outlets considered. More specifically on average, students' do the following activities on a regular basis: visit ecological websites for information, follow news blogs, watch television programs on broad science, read borrowed or purchased books on broad science, visit websites for broad science, read magazines and science articles in newspapers, and last but not least, attend science clubs. However, reading books and visiting websites on broad science seem to represent the two activities with the lowest mean consumptions among students, suggesting that they rely relatively less on those two media sources for their information.

\footnotetext{
${ }^{4}$ Estimated across all OECD countries and partner countries/economies, the ESCS index was created on the basis of the following variables: the International Socio-Economic Index of Occupational Status (ISEI); the highest level of education of the student's parents, converted into years of schooling; the PISA index of family wealth; the PISA index of home educational resources; and the PISA index of possessions related to "classical" culture in the family home. For more information see (OECD, 2017, pp. 339-340)
} 


\subsubsection{Absolute Frequency Distributions for Awareness and Expectations}

The absolute frequencies of students awareness and expectations about the two environmental issues of deforestation and species extinction are presented in figure (1). With regard to deforestation (SEAD), the greatest share of the student respondents show familiarity, with $44.1 \%$ of them reporting being able to provide detailed explanation, followed $34.8 \%$ reporting knowing something about the issue, and able to provide general explanation, and then $14.9 \%$ reporting having heard of the issue, but unable to explain it, while the remaining students ( $6.1 \%$ ) report having never heard of the issue. With regards to students expectations about the evolution of this issue for the next 20 years (SEED), over half of the student respondents, or $57 \%$ feel optimistic, and believe the issue will improve, while $22 \%$ of them believe it will remain the same, and the remaining $20.9 \%$ feel pessimistic, believing it will get worse.

Similar results are observed with regards to the issue of species (plant and animal) extinction (SEASE). The majority of students (46.6\%) report being familiar with this issue, and able to provide detailed explanation, followed 35.7\% reporting knowing something about the issue, and able to provide general explanation, and then $13.7 \%$ reporting having heard of the issue, but unable to explain it, while the remaining students ( $4.1 \%$ ) reports having never heard of the issue. With regards to expectations about the evolution of this issue of species extinction (SEESE) for the next 20 years, over half of the student respondents, or $52.5 \%$ feel optimistic, and believe the issue will improve, while $27.3 \%$ of them believe it will remain the same, and the remaining $20.2 \%$ feel pessimistic believing it will get worse.

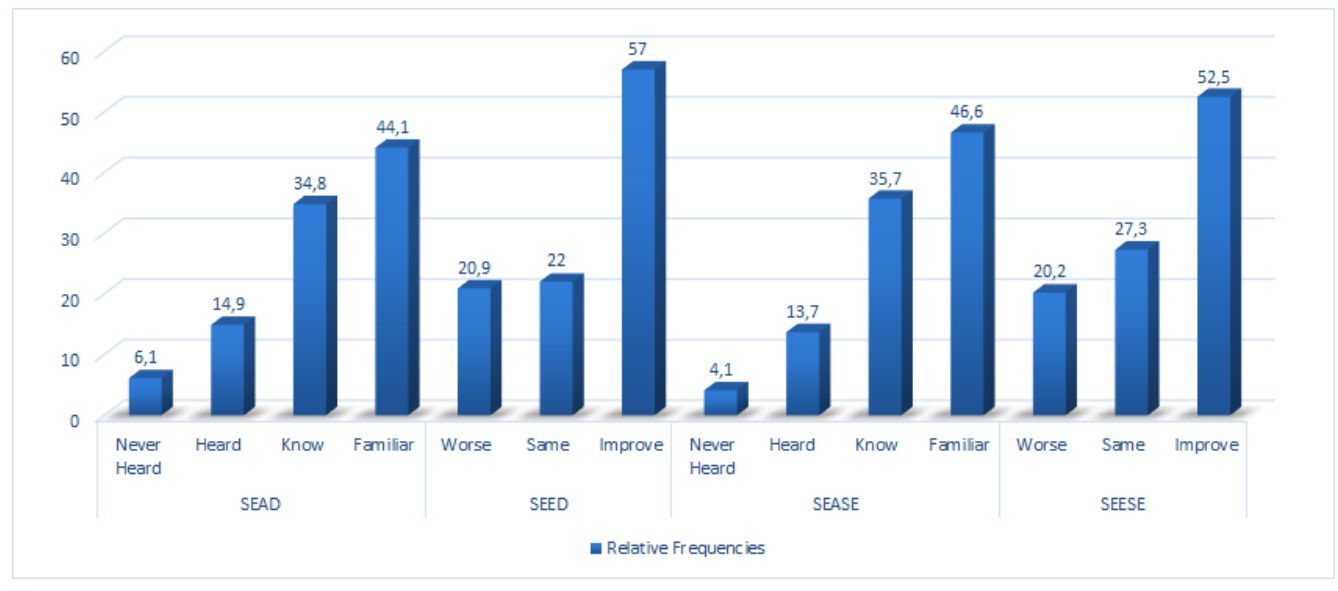

Figure 1: Absolute Relative Frequencies of Awareness and Expectation

\subsubsection{Conditional Frequency Distributions For Awareness and Expectations, by Region}

Breaking the relative frequency distributions into their regional components, as a way of comparing the distribution in the Middle East (UAE, Qatar) to that of North America (USA, Canada), 
we represent the conditional relative frequency distributions by region, for students awareness and expectations about the two environmental issues of deforestation, and species extinction as seen in figure (2). In our studied sample, 11884 of the students come from the Middle East Region, while the remaining 13673 students come from North America, for a total sample size of 25557 students.

With regards to the issue of deforestation, figure (2) shows that $50.4 \%$ of the $44.1 \%$ sample respondents that reported being familiar with this issue, come from North America, while the remaining $49.6 \%$ come from the Middle East. In addition, of the $34.8 \%$ that reported knowing something about the issue, and able to provide general explanation, more than half ( $60.9 \%)$ come from North America, while the remaining 39.1\% come from the Middle East. Furthermore, of the $14.9 \%$ that reported having heard of the issue, but unable to explain it, $52.1 \%$ come from North America, while the remaining 47.9\% come from the Middle East. Finally, of the $6.1 \%$ that reported having never heard of the issue, the vast majority $62.7 \%$ come from the middle east, while the remaining 37.3\% come from North America. Overall the comparison between the two regions seems to suggest relatively more awareness of the issue of deforestation in North America, than the Middle East, and this can be seen at every level of Awareness (SEAD).

In relation to students expectations about the issue of deforestation in the Middle East and North America, figure (2) also show that $62.6 \%$ of the $57 \%$ that felt optimistic, come from North America, against $37.4 \%$ of those optimistic students coming from the Middle East. In addition, of the $22 \%$ that believed the issue of deforestation will remain the same over the next 20 years, the greater share $51.7 \%$ come from North America, while the remaining $48.3 \%$ come from the Middle East. Finally, of the $20.9 \%$ that felt pessimistic about this issue, the greater majority come from the Middle East at 69.6\%, against only 30.4\% from North America. Overall the comparison between the two regions seems to suggest relatively more optimism about the issue of deforestation in North America, than the Middle East, and this can be seen at every level of students expectations (SEED).

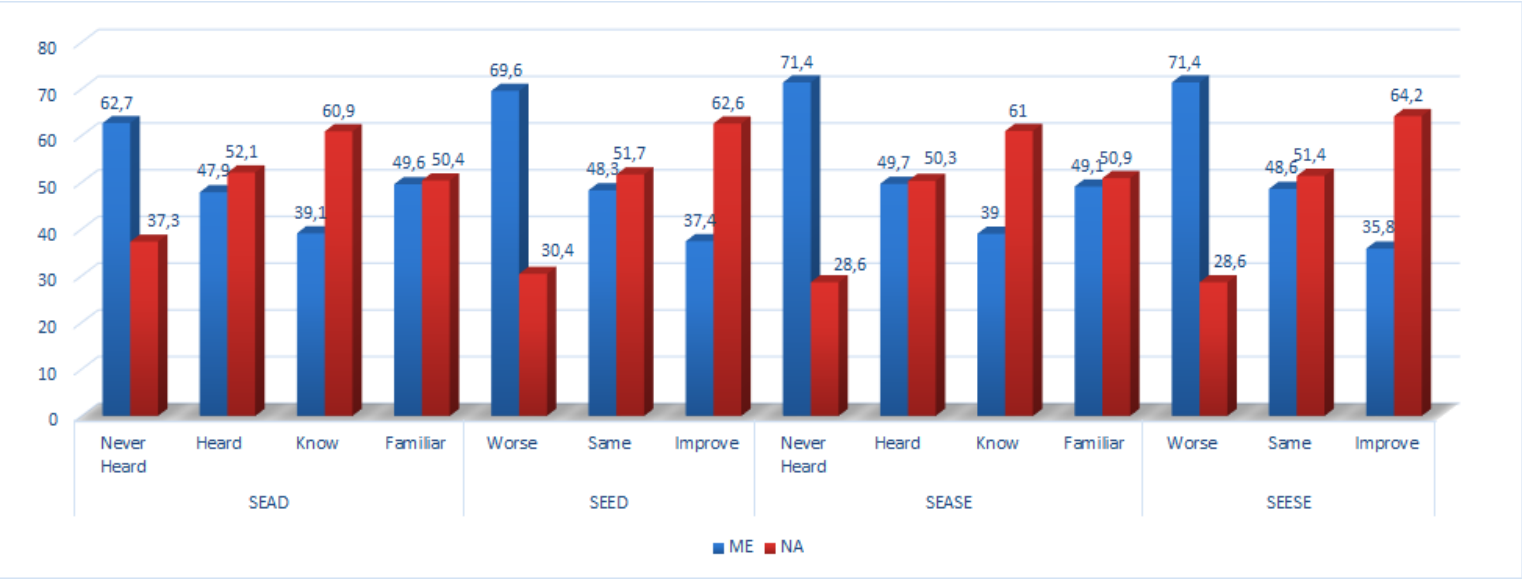


Figure 2: Conditional Relative Frequencies of Awareness and Expectation by Region

Moving now to the issue of species extinction, figure (2) shows that $50.9 \%$ of the $46.6 \%$ sample respondents that reported being familiar with this issue, come from North America, while the remaining $49.1 \%$ come from the Middle East. In addition, of the $35.7 \%$ that reported knowing something about the issue, and able to provide general explanation, more than half ( $61 \%$ ) come from North America, while the remaining 39\% come from the Middle East. Furthermore, of the $13.7 \%$ that reported having heard of the issue, but unable to explain it, $50.3 \%$ come from North America, while the remaining $49.7 \%$ come from the Middle East. Finally, of the $4.1 \%$ that reported having never heard of the issue, the vast majority $71.4 \%$ come from the middle east, while the remaining 28.6\% come from North America. Overall the comparison between the two regions seems to suggest the same observation as the first issue, that is relatively more awareness of the issue of plant and animal extinction in North America, than the Middle East, and this once more can be seen at every level of Awareness (SEASE).

Finally, In relation to students expectations about the issue of species extinction in the Middle East and North America, figure (2) also show that $64.2 \%$ of the $52.5 \%$ that felt optimistic, come from North America, against 35.8\% of those optimistic students coming from the Middle East. In addition, of the $27.3 \%$ that believed the issue of species extinction will remain the same over the next 20 years, the greater share $51.4 \%$ come from North America, while the remaining $48.6 \%$ come from the Middle East. Finally, of the $20.2 \%$ that felt pessimistic about this issue, the greater majority come from the Middle East at 71.4\%, against only 28.6\% from North America. Overall the comparison between the two regions seems to also suggest relatively more optimism about the issue of species extinction in North America, than the Middle East, and this can also be seen at every level of students expectations (SEESE).

\subsubsection{Conditional Frequency Distributions for Awareness and Expectations, by Country}

To compare the distributions of awareness and expectations in the four countries (UAE, Qatar, USA, Canada), we represent the conditional relative frequency distributions by country, for students awareness and expectations about the two environmental issues of deforestation, and species extinction as seen in figure (3). Of the total 25557 students in our studied sample, 6919 are from the UAE, 4965 are from Qatar, 3197 from the USA, and the remaining 10476 are from Canada.

With regards to the issue of deforestation, figure (3) shows that of the $44.1 \%$ sample respondents that reported being familiar with this issue, the greatest share come from Canada at $39.9 \%$, followed by the UAE at $28.7 \%$, then by Qatar at $20.9 \%$, and finally by the USA at $10.5 \%$. In addition, of the $34.8 \%$ that reported knowing something about the issue of deforestation, and able to provide general explanation, the greatest majority come from Canada at $46.8 \%$, followed by the UAE at $23.5 \%$, then by Qatar at $15.6 \%$, and finally by the USA at $14.1 \%$. Furthermore, of the $14.9 \%$ that reported having heard of the issue of deforestation, but unable to explain it, the majority come 
from Canada at 37\%, followed by the UAE at 26.5\%, then by Qatar at $21.5 \%$, and finally by the USA at $15.1 \%$. Finally, of the $6.1 \%$ that reported having never heard of the issue of deforestation, the vast majority come from the UAE at 37.2\%, followed by Canada at $25.7 \%$, then by Qatar at $25.5 \%$, and finally by the USA at $11.6 \%$. Overall the comparison between the four countries seems to suggest relatively more awareness of the issue of deforestation in Canada, followed by the UAE, then Qatar, and finally by the USA; this result is fairly consistent across most awareness levels (SEAD), although UAE students are the most represented among the least aware of the issue of deforestation in our study sample.

In relation to students expectations about the issue of deforestation in the four countries, figure (3) also show that of the $57 \%$ that felt optimistic, the majority (49.3\%) come from Canada, followed by the UAE at $21.4 \%$, then by Qatar at $15.5 \%$, and finally by the USA at $13.3 \%$. In addition, of the $22 \%$ that believed the issue of deforestation will remain the same over the next 20 years, the greater share $38.3 \%$ come from Canada, followed by the UAE at $29.8 \%$, then by Qatar at $18.5 \%$, and finally by the USA at $13.5 \%$. Finally, of the $20.9 \%$ that felt pessimistic about this issue, the greater majority come from the UAE at 39.6\%, followed by Qatar at 29.9\%, then by Canada at $21.2 \%$, and finally by the USA at $9.3 \%$. Overall the comparison between the four countries seems to suggest relatively more optimism about the issue of deforestation (SEED) in Canada, followed by the UAE, then by Qatar, and finally the USA. However, as in the Awareness case, UAE students are the most represented among the most pessimistic students in our study sample.

Moving now to the issue of species extinction, figure (3) shows that of the $46.6 \%$ sample respondents that reported being familiar with this issue, the great majority come from Canada $(39.1 \%)$, followed by the UAE (30.1\%), then by Qatar (19\%), and finally by the USA (11.8\%). In addition, of the $35.7 \%$ that reported knowing something about the issue of species extinction, and able to provide general explanation, the majority (47.3\%) come from Canada, followed by the UAE (24.4\%), then by Qatar (14.6\%), and finally by the USA (13.7\%). Furthermore, of the $13.7 \%$ that reported having heard of the issue of species extinction, but unable to explain it, the vast majority come from Canada (37.0\%), followed by Qatar (27.3\%), then by UAE ( $22.4 \%$ ), and finally by the USA (13.3\%). Finally, of the $4.1 \%$ that reported having never heard of the issue of species extinction, the vast majority $40.7 \%$ come from Qatar, followed by the UAE (30.8\%), then by Canada (20.9\%) and finally by the USA (7.7\%). Overall the comparison between the four countries does not seem to suggest a clear and consistent pattern across all levels of awareness (SEASE). 


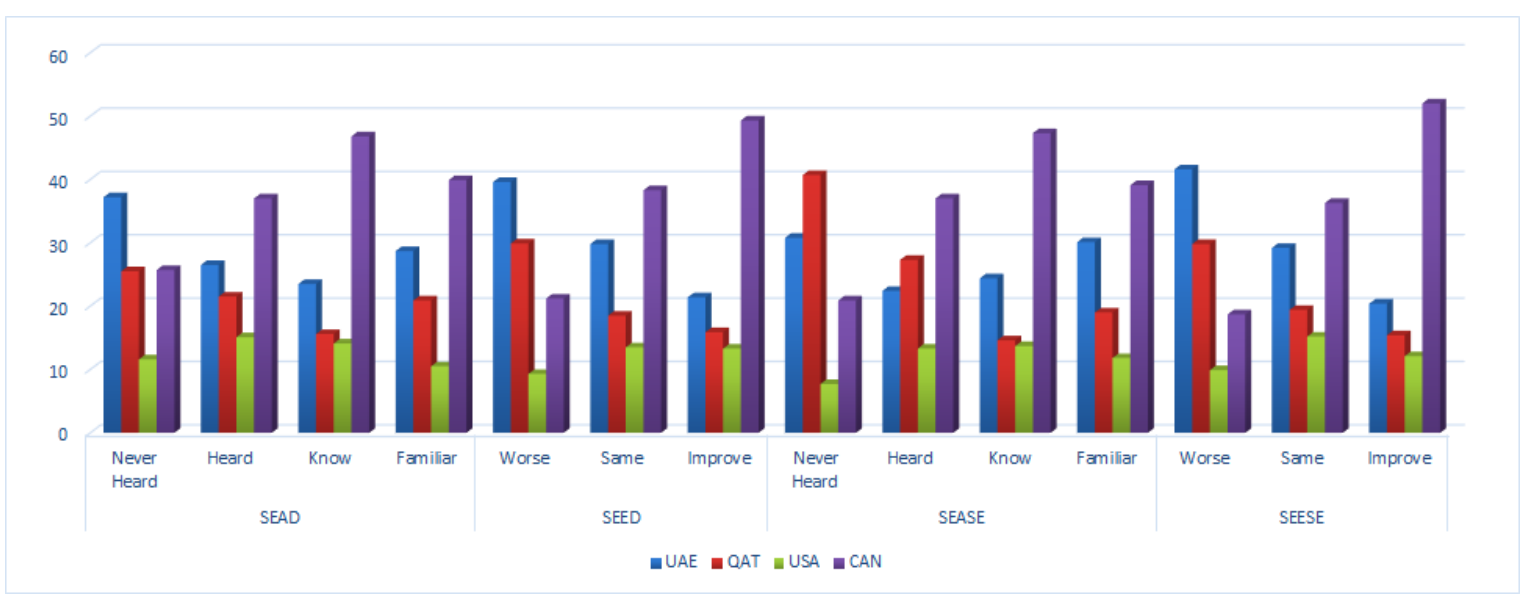

Figure 3: Conditional Relative Frequencies of Awareness and Expectation by Country

Finally, In relation to students expectations about the issue of species extinction in the four countries, figure (3) also show that of the $52.5 \%$ that felt optimistic, the majority (52\%) come from Canada, followed by the UAE (20.4\%), then by Qatar (15.4\%), and finally by the USA (12.1\%). In addition, of the $27.3 \%$ that believed the issue of species extinction will remain the same over the next 20 years, the greater share (36.3\%) come from Canada, followed by $29.2 \%$ from the UAE, then by $19.4 \%$ from Qatar, and then by the USA at $15.2 \%$. Finally, of the $20.2 \%$ that felt pessimistic about this issue, the greater majority come from the UAE at $41.6 \%$, followed by Qatar at $29.8 \%$, then by Canada at $18.7 \%$, and then by the USA at $9.9 \%$. Overall the comparison between the four countries seems to suggest relatively more optimism about the issue of species extinction (SEESE) among Canadian students, followed by students in the UAE, then by Qatari students, and finally students in the USA. Although it should be also noted that the UAE and Qatar show the greatest shares respectively compared to Canada and USA, among the most pessimistic students.

\subsection{Econometric Results}

\subsubsection{The Effects of Media diet on Environmental Awareness}

Media diet is seen to have varying effects on environmental awareness depending on the type of media consumed. Consistently across both environmental issues, tables (2) and (3) show that mainly face-to-face, and print-based media types positively impact students' environmental awareness, while television and internet based media seem to have adverse effects.

In fact, focusing on the traditional face-to-face and print media, we see that increased science club attendance raises students awareness about the issue of deforestation by $15.7 \%$ and species extinction by $22 \%$. Similarly increased frequency of broad science book reading raises students awareness about the issue of deforestation by $11.4 \%$, and species extinction by $10.6 \%$. Conversely however increased media consumption from all the other media types is seen to adversely impact 
students' awareness about both issues. For instance increased frequency of broad science viewing on television reduces the average students' awareness about deforestation by $11 \%$, and species extinction by $10 \%$. A similar adverse effect is observed with increased ecological website visits, which reduces students' awareness of deforestation by $3.5 \%$, and species extinction by $1.2 \%$. Similarly for frequent news blogs visits, which reduces students' awareness of deforestation by $4.1 \%$ and species extinction by $6.1 \%$; Followed by increased general web browsing on broad science that seems to reduce students' awareness of deforestation by $16.1 \%$ and species extinction by $12.3 \%$. Finally increased frequency of magazines and science article reading in newspapers also reduces students' awareness about deforestation by $3.9 \%$, and species extinction by $7.3 \%$.

The regionally mediated media diet effects in the bottom of tables (2) and (3) suggest significant regional differences, in the effect of media consumption on students' awareness about the two environmental issues.

In fact we observe that compared to students in North America, those in the Middle East with increased ecological website visits have respectively $16 \%$ more awareness about the issue of deforestation, and $12.4 \%$ more awareness about the issue of species extinction. Similarly, compared to students in North America, those in the Middle East with increased broad science television program viewing have respectively $11.5 \%$ more awareness about both deforestation, and species extinction.

On the other hand the regionally mediated effects of science club attendance, and general web browsing on broad science are mixed. The former shows a $4.6 \%$ increase in Middle Eastern students' awareness about deforestation compared to their North American counterpart, and a 5.8\% decrease in relative awareness about species extinction; while the later shows a $6.8 \%$ relative decrease in middle eastern students' awareness about deforestation, and a 3.2\% increase in relative awareness of species extinction. Conversely, compared to North American students, those in the Middle East with increased news blog visits are respectively $4.5 \%$ less aware of the issue of deforestation, and $2.2 \%$ less aware of the issue of species extinction; while those with increased broad science book reading are $9.3 \%$ less aware of the issue of deforestation, and 5.6\% less aware of the issue of species extinction.

\subsubsection{The Effects of Media diet on Environmental Expectations (Optimism)}

Media Diet is also seen to significantly affect students expectations about the evolution of deforestation and species extinction for the next 20 years. In fact, we see from tables (2) and (3) that increased frequency of ecological website visits leads to $7.4 \%$ more optimism about both issues. The same observation is made about broad science reading in books which is also seen to raise student optimism about deforestation by $12 \%$, and species extinction by $1.5 \%$. Similarly for increased magazines and science article reading in newspapers, and increased frequency of science club attendance. The former is seen to raise students' optimism by $4.9 \%$ for deforestation, and $4.6 \%$ for species extinction, while the later raises students' optimism by $10.5 \%$ for deforestation 
and $9.4 \%$ for species extinction.

Although increased frequency of web browsing on broad science seems to reduce students' optimism about deforestation by $6.4 \%$, it raises students' optimism about species extinction by $0.8 \%$. On the other hand, increased frequencies of news blogs visits and broad science viewing on television consistently reduce students' environmental optimism. In fact, the former reduces students' optimism about deforestation by $1.9 \%$, and species extinction by $4.1 \%$, while the later reduces students' optimism about deforestation by $1.1 \%$, and species extinction by $5.6 \%$.

The regionally mediated media diet effects in the bottom of tables (2) and (3) further suggest significant regional differences between the middle east and North America, in the effect of media consumption on students' expectations about the two environmental issues.

In fact we observe that compared to students in North America, those in the Middle East with increased ecological website visits are respectively $4.8 \%$ more optimistic about the issue of deforestation, and 5.9\% more optimistic about the issue of species extinction. Similarly, compared to students in North America, those in the Middle East with increased broad science television program viewing are respectively 3.2\% more optimistic about the issue of deforestation, and $9.4 \%$ more optimistic about the issue of species extinction. On the other hand the regionally mediated effects of broad science book reading is mixed, and show 7.4\% less optimism about deforestation for Middle Eastern students' compared to their North American counterpart, but $4.0 \%$ more optimism about species extinction. Conversely, compared to North American students, those in the Middle East with increased news blog visits are respectively $2.6 \%$ less optimistic about the issue of deforestation, and 3.1\% less optimistic about the issue of species extinction; similarly for those with increased broad science book reading, which are $7.4 \%$ less optimistic about the issue of deforestation, and $6.3 \%$ less optimistic about the issue of species extinction. Finally, although the regionally mediated effect of science club attendance does not significantly affect in students' expectation about deforestation, it is found to have a significant adverse effect on students' expectation about the issue of species extinction, reducing students' optimism by $2.6 \%$.

\subsubsection{The Effects of the Control Variables on Environmental Awareness}

Starting with the coefficient value of the regional dummy variable, the results on tables (2) and (3) show that compared to North American students, those in the Middle East are 14.2\% less aware of the issue of Deforestation, and 38.9\% less aware of the issue of species extinction. Similarly compared to females students, males are $4.7 \%$ less aware of the issue of deforestation, but $5.8 \%$ more aware about the issue of species extinction. Conversely however, students' increased interest in ecosystem services and sustainability consistently impact positively their environmental awareness, at a level of $21.8 \%$ for the issue of deforestation, and $12.4 \%$ for the issue of species extinction. Similarly for students' increased interest in how science can help prevent diseases, which positively affects awareness about deforestation by $7.7 \%$, and species extinction by $12.6 \%$.

The results of the socio-demographic control variables suggest that on average a one year 
increase in age leads to a $20.4 \%$ increase in students' awareness of the issue of deforestation, and a $9.8 \%$ increase in the students' awareness of the issue of species extinction. Furthermore, an increase in students' normalized index of economic, social, and cultural status is found to increase students' awareness of the issue of deforestation by $16.9 \%$, and that of species extinction by $12.7 \%$. With regards to immigration status, the results show that compared to native students, first generation immigrant (expatriate) students are 3.9\% more aware of the issue of deforestation, and $6.6 \%$ more aware of the issue of species extinction. However, these figures for second generation expatriate students are $0.99 \%$ less awareness of the issue of deforestation, but $2.5 \%$ more awareness of the issue of species extinction.

\subsubsection{The Effects of the Control Variables on Environmental Expectations (Optimism)}

The results on tables (2) and (3) show that students' increased interest in ecosystem services and sustainability have mixed effects on their environmental expectations, reducing students' optimism about the issue of deforestation by $2 \%$, while increasing their optimism about the issue of species extinction by $2.4 \%$. All the remaining control variables have consistent effects across the two environmental issues. For instance, compared to students in North America, those in the Middle East are $14.2 \%$ less optimistic about the issue of deforestation, and $59.0 \%$ less optimistic about the issue of species extinction. Similarly, compared to females students, males are $24.4 \%$ less optimistic about the issue of deforestation, and $28.4 \%$ less optimistic about the issue of species extinction. In addition, looking at the coefficient values on students' immigration status, we note that compared to native students, first generation immigrants (expatriates) are 16.6\% less optimistic about the issue of deforestation, and 3.8\% less optimistic about the issue of species extinction, while second generation expatriates are $0.9 \%$ more optimistic about the issue of deforestation, and $5.9 \%$ more optimistic about the issue of species extinction. Furthermore, increased students' interest in how science can help prevent diseases leads to a $4.4 \%$ increase in students' optimism about the issue of deforestation, and a 3.3\% increased optimism about the issue of species extinction. Similarly, a one year increase in age raises students' optimism by $3.8 \%$ for the case of deforestation, and $6.3 \%$ for the case of species extinction. Also, an increase in students' normalized index of economic, social, and cultural status is found to consistently raise students' optimism by $10.9 \%$ for the issue of deforestation, and $12.7 \%$ for the issue of species extinction. Finally, the recursive effects of students' awareness on their expectations about the two environmental issues suggest that every one level increase in awareness raises students' optimism by $20.4 \%$ for the issue of deforestation, and $15.0 \%$ for the issue of species extinction. 
Table 1: Summary Description of the Explanatory factors of Awareness and Expectations

\begin{tabular}{|c|c|c|c|}
\hline Variables & $\mathrm{N}=25557$ & Mean & s.d. \\
\hline \multicolumn{4}{|l|}{ Media Diet } \\
\hline EcoWebVisit & How often visit Ecological Websites; & & \\
\hline BlogsVisit & $\begin{array}{l}\text { 1- never or Hardly, 2- sometimes, 3-regularly, 4-very often. } \\
\text { How often follow news via blogs; }\end{array}$ & 3.27 & 0.91 \\
\hline BroadScTVprog & $\begin{array}{l}\text { 1- never or Hardly, 2- sometimes, 3-regularly, 4-very often. } \\
\text { How often watch TV program on broad science; }\end{array}$ & 3.11 & 0.98 \\
\hline BroadScBooks & $\begin{array}{l}\text { 1- never or Hardly, 2- sometimes, 3-regularly, 4-very often. } \\
\text { How often read books on broad science; }\end{array}$ & 2.84 & 0.93 \\
\hline \multirow[t]{2}{*}{ BroadScWeb } & $\begin{array}{l}\text { 1- never or Hardly, 2- sometimes, 3-regularly, 4-very often. } \\
\text { How often visit websites on broad science; }\end{array}$ & 3.19 & 0.90 \\
\hline & $\begin{array}{l}\text { 1- never or Hardly, 2- sometimes, 3-regularly, 4-very often. } \\
\text { How often read magazines and science articles; }\end{array}$ & 2.91 & 0.96 \\
\hline \multirow[t]{2}{*}{ ScClubAttend } & $\begin{array}{l}\text { 1- never or Hardly, 2- sometimes, 3-regularly, 4-very often. } \\
\text { How often attend science club; }\end{array}$ & 3.10 & 0.93 \\
\hline & 1- never or Hardly, 2- sometimes, 3-regularly, 4-very often. & 3.49 & 0.84 \\
\hline $\begin{array}{l}\text { Regional and Interests } \\
\text { MENA }\end{array}$ & Binary recional Indicator cantures cultural difforences. & & \\
\hline IntBiosph & $\begin{array}{l}=0 \text { if student is from North America, } 1 \text { if Middle East. } \\
\text { Level of interest in the Biosphere, } \\
\text { (Ecosystem services and Sustainability); }\end{array}$ & 0.46 & 0.50 \\
\hline IntScPrevDis & $\begin{array}{l}\text { 0- Don't know what it is, 1- not interested, 2-Hardly interested, } \\
3 \text {-Interested, 4-highly interested. } \\
\text { Level of Interest in how science can help prevent disease; } \\
\text { 0- Don't know what it is, 1- not interested, 2-Hardly interested, } \\
\text { 3-Interested, 4-highly interested. }\end{array}$ & 3.99 & 1.07 \\
\hline \multicolumn{4}{|l|}{ Socio-demographics } \\
\hline AGE & students' age. & 15.80 & 0.29 \\
\hline Gender & Gender; 0-Female , 1-Male. & 1.46 & 0.50 \\
\hline $\begin{array}{l}\text { ESCS } \\
\text { IMMIG }\end{array}$ & $\begin{array}{l}\text { Normalized PISA Index of economic, social and cultural status. } \\
\text { Student Immigration status; }\end{array}$ & 0.56 & 0.77 \\
\hline & 1-Native, 2-Second-generation, 3- First-generation. & 1.66 & 0.85 \\
\hline WFSTUWT & $\begin{array}{l}\text { Student final weight in the Data } \\
\text { (used for correct estimation of dispersion measures) }\end{array}$ & 84.97 & 213.39 \\
\hline
\end{tabular}

Source: Programme for International Student Assessment (PISA 2015) Data set. 
Table 2: MLE Results for Awareness and Expectation about the Issue of Deforestation

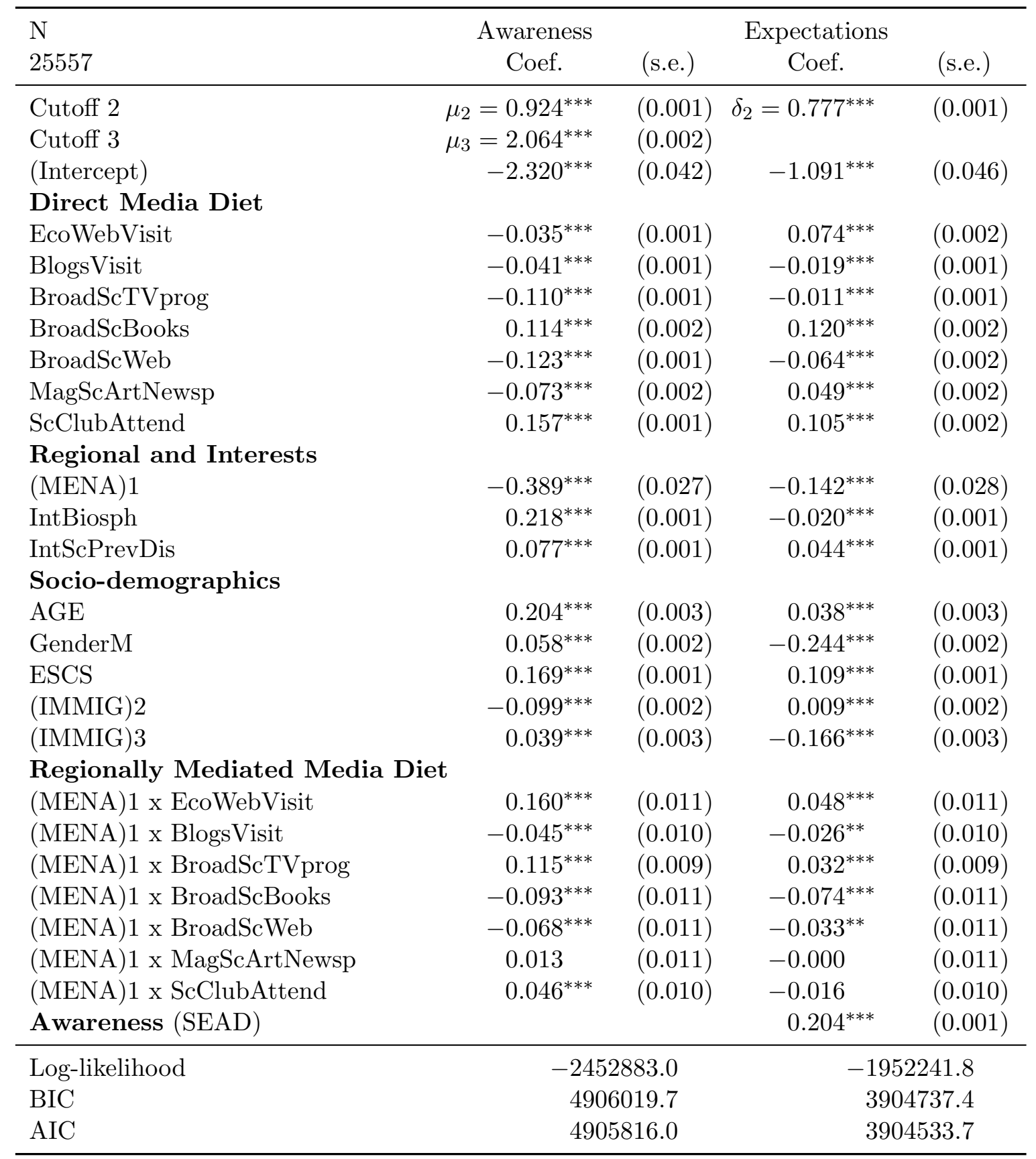

${ }^{* * *} p<0.001,{ }^{* *} p<0.01,{ }^{*} p<0.05$ 
Table 3: MLE Results for Awareness and Expectation about the issue of Species Extinction

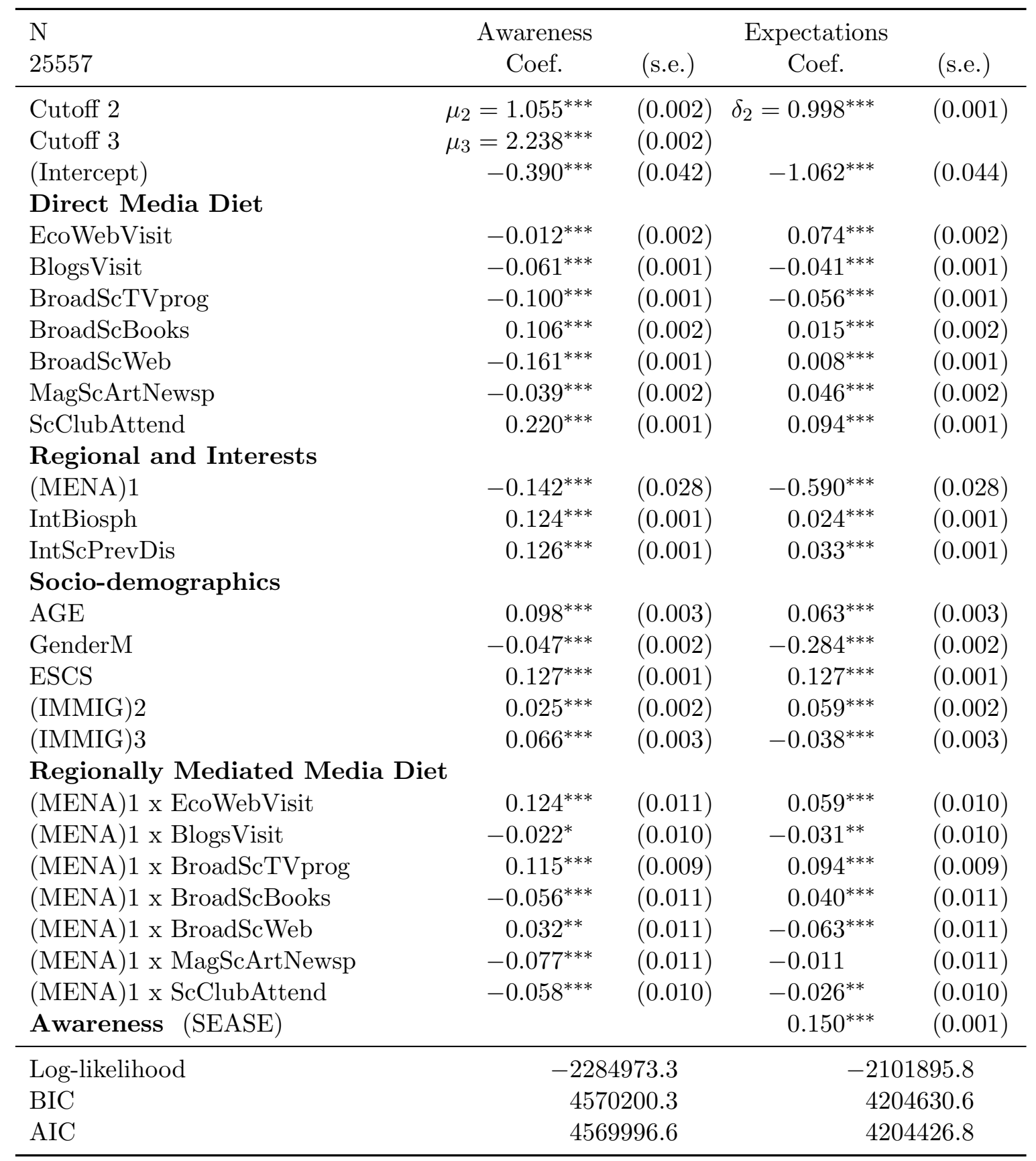

${ }^{* * *} p<0.001,{ }^{* *} p<0.01,{ }^{*} p<0.05$ 


\section{Conclusion and Discussion}

This study inscribed itself in the global discussion about the issue of environmental awareness, beliefs and behaviors; here we focused on the role that cultural differences and scientific media dieting play in explaining heterogeneities in students' awareness and expectations about the two environmental issues of deforestation and species extinction in the Middle East and North America. To this end, we used a cross-sectional survey data of the OECD's Program for International Student Assessment (PISA) 2015, to provide a comparative analysis of the two regions.

The results showed that students' scientific media diet does significantly affect their awareness and expectations about the environmental issues of deforestation and species extinction, in the Middle East and North America. However, the different media types considered presented significant heterogeneities in their effects on students' environmental awareness and optimism. Only science club attendance and broad science reading in books are found to be effective at raising students awareness about the two environmental issues of deforestation and species extinction, while the remaining media types presented adverse effects.

From the later group, we noted that television programs on broad science did not stress enough the issues of deforestation and species extinction; a similar observation was made for ecological websites, and broad science content delivered through the internet. As such, ecological websites need to review their contents to not only promote ecological services, but also to raise awareness about the challenges facing the natural environment including forests, plants and animals. Similarly, broad science content delivered through the internet, should not only promote scientific discoveries, but also provide enough content to raise awareness about our contemporary environmental challenges in general, deforestation and species extinction in particular.

Furthermore, the results demonstrated the existence of significant regional heterogeneities in students awareness and expectations about both environmental issues, with less awareness and less optimism found among students in the Middle Eastern region, compared to their North American Counterpart. In fact, compared to North American students, those in the Middle East were found to be $14.2 \%$ less aware of the issue of deforestation, and $38.9 \%$ less aware of the issue of plants and animals extinction. Similarly for students' Environmental expectation, we found that compared to North American students, those in the Middle East are 14.5\% less optimistic about the issue of deforestation, and $59.0 \%$ less optimistic about the issue of species extinction.

These differences in Awareness and Expectations captured by the regional dummy variable "MENA" reflect the influences of unobserved cultural factors (social, religious, and political) uniquely characterizing each of the two regions, as previously discussed in section (2.2). These observed differences might also be reflecting differences in the significance of these two specific environmental issues for the two regions under consideration. In fact, it should be noted that Middle Eastern countries, especially the UAE and Qatar are characterized by a desert/arid climate, and therefore do not have much forest coverage, while North American countries with a more diversi- 
fied climate have more forest coverage. This difference in forest coverage between the Middle East and North America could potentially lead to differing interests on forest related issues in the two regions, thereby explain the observed differential awareness and expectations about the issues of deforestation. A similar argument could be made about the issue of species (plant and animal) extinction.

Beyond any cultural and/or geographic/climatic differences however, world citizens share one single and unique planet, and the systemic relationship between all life on earth, be it human, animal or plant, call upon our collective conscience to act together on resolving all our contemporary environmental challenges. Since economic theory can become self fulfilling (Ferraro et al., 2005), and also because we can explain how expectations are formed, by advancing the hypothesis that they are essentially the same as the predictions of the relevant economic theory (Muth, 1961), we can see expectations as also self-fulfilling, such that raising young people's environmental awareness and optimism through proper communication strategies, would be invaluable for achieving an economic development in line with our need to preserve our natural environment and ecosystem services for generations to come. 


\section{Appendix}

The log-likelihood of an individual observation $i$ is then

$$
\ln L_{i}=\sum_{j=1}^{4} \sum_{j=1}^{3} I\left(S E A_{i}=j, S A E_{i}=k\right) \ln \operatorname{Pr}\left(S E A_{i}=j, S A E_{i}=k\right)
$$

If we further assume independence of the individual observations, then we can sum the equations in (6) across all individuals and obtain the log-likelihood for the entire sample of size $N$ as:

$$
\ln \mathbf{L}=\sum_{i=1}^{N} \sum_{j=1}^{4} \sum_{j=1}^{3} I\left(S E A_{i}=j, S A E_{i}=k\right) \ln \operatorname{Pr}\left(S E A_{i}=j, S A E_{i}=k\right)
$$

The model is identified using full-information maximum likelihood methods. In order to ensure that the cutoffs are ordered in ascending fashion, and also that $-1 \leq \rho \leq+1$, we define the following parameters: $r=\arctan (\rho)$; Therefore the complete set of parameters to be estimated is:

$$
\Theta \equiv\left\{\beta_{1}, \beta_{2}, \gamma, r, \mu_{1}, \mu_{2}, \mu_{3}, \delta_{1}, \delta_{2}\right\}
$$

Then the analytical first and second order conditions of the log-likelihood function in equation (6) is obtained with respect to $\theta \in \Theta$ :

$$
\frac{\partial \ln L}{\partial \theta}=\frac{1}{L}\left(\frac{\partial \Phi_{2}\left(B_{11}, B_{21}, \rho^{\prime}\right)}{\partial \theta}-\frac{\partial \Phi_{2}\left(B_{12}, B_{22}, \rho^{\prime}\right)}{\partial \theta}-\frac{\partial \Phi_{2}\left(B_{13}, B_{23}, \rho^{\prime}\right)}{\partial \theta}+\frac{\partial \Phi_{2}\left(B_{14}, B_{24}, \rho^{\prime}\right)}{\partial \theta}\right)
$$

Where the following notation is adopted:

$$
\begin{aligned}
& B_{11}=B_{13}=\mu_{j}-\beta_{1}^{\prime} X_{1 i} \\
& B_{12}=B_{14}=\mu_{j-1}-\beta_{1}^{\prime} X_{1 i} \\
& B_{21}=B_{22}=\zeta\left(\delta_{k}-\gamma \beta_{1}^{\prime} X_{1 i}-\beta_{2}^{\prime} X_{1 i}\right) \\
& B_{23}=B_{24}=\zeta\left(\delta_{k-1}-\gamma \beta_{1}^{\prime} X_{1 i}-\beta_{2}^{\prime} X_{1 i}\right)
\end{aligned}
$$

Also

$$
\Phi^{s} \equiv \Phi_{2}\left(B_{1 s}, B_{2 s}, \tilde{\rho}\right) \text { for } s=1 \ldots 4
$$

Hence the first partial derivatives of the bivariate standard normal cumulative density function are obtained as: 


$$
\begin{aligned}
& \Phi_{1}^{s}=\phi\left(B_{1 s}\right) F\left(\frac{B_{2 s}-\tilde{\rho} B_{1 s}}{\sqrt{1-\tilde{\rho}^{2}}}\right) \\
& \Phi_{2}^{s}=\phi\left(B_{2 s}\right) F\left(\frac{B_{1 s}-\tilde{\rho} B_{2 s}}{\sqrt{1-\tilde{\rho}^{2}}}\right) \\
& \Phi_{3}^{s}=\frac{1}{2 \pi \sqrt{1-\tilde{\rho}^{2}}} \exp ^{-\frac{1}{2}\left(\frac{B_{1 s}^{2}+B_{2 s}^{2}-2 \tilde{\rho} B_{1 s} B_{2 s}}{1-\tilde{\rho}^{2}}\right)}
\end{aligned}
$$

And the derivatives of $B_{1 s}, B_{2 s}$ and $\tilde{\rho}$ with respect to each parameter given as:

$$
\begin{aligned}
& \frac{\partial B_{1 s}}{\partial \beta_{1}}=-1 \\
& \frac{\partial B_{1 s}}{\partial \mu_{1}}=1 \\
& \frac{\partial B_{1 s}}{\partial \mu_{2}}=2 \mu_{2} \\
& \frac{\partial B_{1 s}}{\partial \mu_{3}}=2 \mu_{3} \\
& \frac{\partial B_{2 s}}{\partial \beta_{1}}=-\zeta \gamma \\
& \frac{\partial B_{2 s}}{\partial \beta_{2}}=-\zeta \\
& \frac{\partial B_{2 s}}{\partial r}=-B_{2 s} \zeta^{2} \gamma \frac{d \rho}{d r} \\
& \frac{\partial B_{2 s}}{\partial \gamma}=-B_{2 s} \zeta \tilde{\rho}-\zeta \beta_{1} \\
& \frac{\partial B_{2 s}}{\partial \delta_{1}}=\zeta \\
& \frac{\partial B_{2 s}}{\partial \delta_{2}}=2 \zeta \delta_{2}
\end{aligned}
$$




$$
\begin{aligned}
& \frac{\partial \tilde{\rho}}{\partial r}=\zeta(1-\zeta \gamma \tilde{\rho}) \frac{d \rho}{d r} \\
& \frac{\partial \tilde{\rho}}{\partial \gamma}=\zeta\left(1-\tilde{\rho}^{2}\right) \\
& \frac{\partial \rho}{\partial r}=4 \frac{e x p^{2 r}}{\left(1+e x p^{2 r}\right)^{2}}
\end{aligned}
$$

The second order conditions are obtained as follows:

$$
\frac{\partial^{2} \ln L}{\partial \theta_{1} \partial \theta_{2}}=L^{-1} \frac{\partial^{2} L}{\partial \theta_{1} \partial \theta_{2}}-L^{-2} \frac{\partial L}{\partial \theta_{1}} \frac{\partial L}{\partial \theta_{2}}
$$

with

$$
\frac{\partial^{2} L}{\partial \theta_{1} \partial \theta_{2}}=\frac{\partial^{2} \Phi_{2}^{1}}{\partial \theta_{1} \partial \theta_{2}}-\frac{\partial^{2} \Phi_{2}^{2}}{\partial \theta_{1} \partial \theta_{2}}-\frac{\partial^{2} \Phi_{2}^{3}}{\partial \theta_{1} \partial \theta_{2}}+\frac{\partial^{2} \Phi_{2}^{4}}{\partial \theta_{1} \partial \theta_{2}}
$$

and using the notation $B_{3 s} \equiv \rho^{\prime}$ we get

$$
\frac{\partial^{2} \Phi_{2}}{\partial \theta_{1} \partial \theta_{2}}=\sum_{i j=1}^{3} \Phi_{i j}^{s} \frac{\partial B_{i s}}{\partial \theta_{1}} \frac{\partial B_{j s}}{\partial \theta_{2}}+\Phi_{1}^{s} \frac{\partial^{2} B_{1 s}}{\partial \theta_{1} \theta_{2}}+\Phi_{2}^{s} \frac{\partial^{2} B_{2 s}}{\partial \theta_{1} \theta_{2}}+\Phi_{3}^{s} \frac{\partial^{2} B_{3 s}}{\partial \theta_{1} \theta_{2}}
$$

With the second derivatives of the bivariate standard cumulative distribution function given as:

$$
\begin{aligned}
\Phi_{11}^{s} & =-B_{1 s} \Phi_{1}^{s}-\tilde{\rho} \Phi_{3}^{s} \\
\Phi_{12}^{s} & =\Phi_{3}^{s} \\
\Phi_{13}^{s} & =\Phi_{3}^{s} \frac{\tilde{\rho} B_{2 s}-B_{1 s}}{1-\tilde{\rho}^{2}} \\
\Phi_{22}^{s} & =-B_{2 s} \Phi_{2}^{s}-\tilde{\rho} \Phi_{3}^{s} \\
\Phi_{23}^{s} & =\Phi_{3}^{s} \frac{\tilde{\rho} B_{1 s}-B_{2 s}}{1-\tilde{\rho}^{2}} \\
\Phi_{33}^{s} & =\Phi_{3}^{s} \frac{B_{1 s} B_{2 s}+\rho^{\prime}-\tilde{\rho} \frac{B_{1 s}^{2}+B_{2 s}^{2}-2 \tilde{\rho} B_{1 s} B_{2 s}}{1-\tilde{\rho}^{2}}}{1-\tilde{\rho}^{2}} \\
\frac{\partial^{2} B_{1 s}}{\partial^{2} \mu_{2}} & =2 \\
\frac{\partial^{2} B_{1 s}}{\partial^{2} \mu_{3}} & =2
\end{aligned}
$$




$$
\begin{aligned}
\frac{\partial^{2} B_{2 s}}{\partial \beta_{1} \partial r} & =\zeta^{3} \gamma^{2} \frac{d \rho}{d r} \\
\frac{\partial^{2} B_{2 s}}{\partial \beta_{1} \partial \gamma} & =\zeta^{2} \gamma \tilde{\rho}-\zeta \\
\frac{\partial^{2} B_{2 s}}{\partial \beta_{2} \partial r} & =\zeta^{3} \gamma \frac{d \rho}{d r} \\
\frac{\partial^{2} B_{2 s}}{\partial \beta_{2} \partial \gamma} & =\zeta^{2} \tilde{\rho} \\
\frac{\partial^{2} B_{2 s}}{\partial r^{2}} & =3 B_{2 s} \zeta^{4} \gamma^{2}\left(\frac{d \rho}{d r}\right)^{2}-B_{2 s} \zeta^{2} \gamma \frac{d^{2} \rho}{d r^{2}} \\
\frac{\partial^{2} B_{2 s}}{\partial r \partial \gamma} & \left.=-3 B_{2 s} \zeta^{2}\left(1 \tilde{\rho}^{2}\right)+\beta_{1} \zeta^{3} \gamma\right) \frac{d \rho}{d r} \\
\frac{\partial^{2} B_{2 s}}{\partial r \partial \delta_{1}} & =-\zeta^{3} \gamma \frac{d \rho}{d r} \\
\frac{\partial^{2} B_{2 s}}{\partial r \partial \delta_{2}} & =-2 \delta_{2} \zeta^{3} \gamma \frac{d \rho}{d r} \\
\frac{\partial^{2} B_{2 s}}{\partial \gamma^{2}} & =B_{2 s}\left(3 \zeta^{3} \gamma \tilde{\rho}-\zeta^{2}\right)+2 \beta_{1} \zeta^{2} \tilde{\rho} \\
\frac{\partial^{2} B_{2 s}}{\partial \gamma \partial \delta_{1}} & =-\zeta^{2} \tilde{\rho} \\
\frac{\partial^{2} B_{2 s}}{\partial \gamma \partial \delta_{2}} & =-2 \delta_{2} \zeta^{2} \tilde{\rho} \\
\frac{\partial^{2} B_{2 s}}{\partial \delta_{2}^{2}} & =2
\end{aligned}
$$




\section{References}

Abbar, Sofiane, Tahar Zanouda, Laure Berti-Equille and Javier Borge-Holthoefer (2016), Using twitter to understand public interest in climate change: The case of qatar., in 'EcoMo@ ICWSM'.

Abokhodair, Norah, Sofiane Abbar, Sarah Vieweg and Yelena Mejova (2017), 'Privacy and social media use in the arabian gulf: Saudi arabian \& qatari traditional values in the digital world', The Journal of Web Science $\mathbf{3}(1)$.

Afifi, Tamara D, Nicole Zamanzadeh, Kathryn Harrison and Micelle Acevedo Callejas (2018), 'Wired: The impact of media and technology use on stress (cortisol) and inflammation (interleukin il-6) in fast paced families', Computers in Human Behavior 81, 265-273.

Al-Badi, Ali H (2014), 'The adoption of social media in government agencies: Gulf cooperation council case study', Journal of Technology Research 5, 1.

Arcury, Thomas (1990), 'Environmental attitude and environmental knowledge', Human organization 49(4), 300-304.

Barnosky, Anthony D, Nicholas Matzke, Susumu Tomiya, Guinevere OU Wogan, Brian Swartz, Tiago B Quental, Charles Marshall, Jenny L McGuire, Emily L Lindsey, Kaitlin C Maguire et al. (2011), 'Has the earth's sixth mass extinction already arrived?', Nature 471(7336), 51.

Beaudoin, Christopher E (2014), 'The mass media and adolescent socialization: A prospective study in the context of unhealthy food advertising', Journalism \& Mass Communication Quarterly $\mathbf{9 1}(3), 544-561$.

Berger, Arthur Asa (2018), Millennials and the media, in 'Cultural Perspectives on Millennials', Springer, pp. 47-62.

Bergström, Annika and Maria Jervelycke Belfrage (2018), 'News in social media: Incidental consumption and the role of opinion leaders', Digital Journalism pp. 1-16.

Boczkowski, Pablo J, Eugenia Mitchelstein and Mora Matassi (2018), “"news comes across when i'm in a moment of leisure": Understanding the practices of incidental news consumption on social media', New Media \& Society p. 1461444817750396.

Bozoglu, Mehmet, Abdulbaki Bilgic, Bakiye Kilic Topuz and Yuksel Ardali (2016), 'Factors affecting the students'environmental awareness, attitudes and behaviors in ondokuz mayis university, turkey', Fresenius Environmental Bulletin 25(4), 1243-1257. 
Bradley, Jennifer Campbell, Tina M Waliczek and Jayne M Zajicek (1999), 'Relationship between environmental knowledge and environmental attitude of high school students', The Journal of Environmental Education 30(3), 17-21.

Bright, Ryan M, Edouard Davin, Thomas O’Halloran, Julia Pongratz, Kaiguang Zhao and Alessandro Cescatti (2017), 'Local temperature response to land cover and management change driven by non-radiative processes', Nature Climate Change 7(4), 296.

Budget, Global Carbon (2016), 'Corinne le quéré et al', Earth Syst. Sci. Data 8, 605-649.

Butler, Lauren M et al. (2018), 'Dance and mixed-media performance for building scientific understanding and environmental respect', Consilience: The Journal of Sustainable Development (19), 183-195.

Ceballos, Gerardo, Andrés García and Paul R Ehrlich (2010), 'The sixth extinction crisis: loss of animal populations and species', Journal of Cosmology 8(1821), 31.

Ceballos, Gerardo, Paul R Ehrlich, Anthony D Barnosky, Andrés García, Robert M Pringle and Todd M Palmer (2015), 'Accelerated modern human-induced species losses: Entering the sixth mass extinction', Science advances 1(5), e1400253.

Ceballos, Gerardo, Paul R Ehrlich and Rodolfo Dirzo (2017), 'Biological annihilation via the ongoing sixth mass extinction signaled by vertebrate population losses and declines', Proceedings of the National Academy of Sciences 114(30), E6089-E6096.

Coelho, Carlyle Mendes, Cristiano Schetini de Azevedo, Marcelo Alcino de Barros Vaz Guimarães and Robert John Young (2016), 'Environmental enrichment effect on fecal glucocorticoid metabolites and captive maned wolf (chrysocyon brachyurus) behavior', Journal of Applied Animal Welfare Science 19(4), 353-362.

Coertjens, Liesje, Jelle Boeve-de Pauw, Sven De Maeyer and Peter Van Petegem (2010), 'Do schools make a difference in their students'environmental attitudes and awareness? evidence from pisa 2006', International Journal of Science and Mathematics Education 8(3), 497-522.

Dawson, Terence P, Stephen T Jackson, Joanna I House, Iain Colin Prentice and Georgina M Mace (2011), 'Beyond predictions: biodiversity conservation in a changing climate', science $332(6025), 53-58$.

Dennis, Everette E., Justin D. Martin and Robb Wood (2017), Media Use in the Middle East, 2017: A Seven-Nation Survey, Northwestern University in Qatar, Retrieved on 02 April 2018 from.

URL: http://www.mideastmedia.org/survey/2017/ 
Edwards, David M, Timothy M Collins and Reiko Goto (2016), 'An arts-led dialogue to elicit shared, plural and cultural values of ecosystems', Ecosystem Services 21, 319-328.

Eichner, Thomas and Rüdiger Pethig (2006), 'Efficient nonanthropocentric nature protection', Social Choice and Welfare 26(1), 47-74.

Engel, Laura C and Matthew O Frizzell (2015), 'Competitive comparison and pisa bragging rights: sub-national uses of the oecd's pisa in canada and the usa', Discourse: Studies in the Cultural Politics of Education 36(5), 665-682.

Esra, ÖZAY (2010), 'The factors that affect attitudes towards environment of secondary school students', Journal of Turkish Science Education 7(3), 198.

Ferraro, Fabrizio, Jeffrey Pfeffer and Robert I Sutton (2005), 'Economics language and assumptions: How theories can become self-fulfilling', Academy of Management review 30(1), 8-24.

Field, Christopher B and Katharine J Mach (2017), 'Rightsizing carbon dioxide removal', Science 356(6339), 706-707.

Fischlin, A, GF Midgley, JT Price, R Leemans, B Gopal, CM Turley, MDA Rounsevell, P Dube, J Tarazona and A Velichko (2007), 'Ecosystems their properties goods and services. climate change 2007: Impacts adaptation and vulnerability. contribution of working group ii to the fourth assessment report of the intergovernmental panel on climate change ml parry of canziani jp palutikof pj van der linden and ce hanson eds. cambridge university press cambridge', Assessment Report of the Intergovernmental Panel on Climate Change 4, 211-272.

Frank, Joshua (2008), 'Is there an "animal welfare kuznets curve"?', Ecological Economics 66(23), 478-491.

Fuller, Graham (2018), A sense of siege: The geopolitics of Islam and the West, Routledge.

Gunawan, I Gede Dharman (2017), 'Character education through education media of dayak and balinese local culture', DAFIS PROCEEDING pp. 232-237.

Houghton, Richard A and Alexander A Nassikas (2018), 'Negative emissions from stopping deforestation and forest degradation, globally', Global change biology 24(1), 350-359.

Irvine, Katherine N, Liz O’Brien, Neil Ravenscroft, Nigel Cooper, Mark Everard, Ioan Fazey, Mark S Reed and Jasper O Kenter (2016), 'Ecosystem services and the idea of shared values', Ecosystem Services 21, 184-193. 
Ives, Christopher D and Dave Kendal (2014), 'The role of social values in the management of ecological systems', Journal of environmental management 144, 67-72.

Jackman, S (2000), 'Models for ordered outcomes [pdf document]', Retrieved on 25 March 2018 from Lecture notes Online Web site: http://www. stanford. edu/class/polisci203/ordered. pdf .

Johansson-Stenman, Olof (2018), 'Animal welfare and social decisions: Is it time to take bentham seriously?', Ecological Economics 145, 90-103.

Kenter, Jasper O (2016), 'Integrating deliberative monetary valuation, systems modelling and participatory mapping to assess shared values of ecosystem services', Ecosystem Services 21, 291307.

Kenter, Jasper O, Liz O’Brien, Neal Hockley, Neil Ravenscroft, Ioan Fazey, Katherine N Irvine, Mark S Reed, Michael Christie, Emily Brady, Rosalind Bryce et al. (2015), 'What are shared and social values of ecosystems?', Ecological Economics 111, 86-99.

Kenter, Jasper O, Niels Jobstvogt, Verity Watson, Katherine N Irvine, Michael Christie and Ros Bryce (2016), 'The impact of information, value-deliberation and group-based decision-making on values for ecosystem services: integrating deliberative monetary valuation and storytelling', Ecosystem Services 21, 270-290.

Kenter, Jasper O, Rosalind Bryce, Michael Christie, Nigel Cooper, Neal Hockley, Katherine N Irvine, Ioan Fazey, Liz O'Brien, Johanne Orchard-Webb, Neil Ravenscroft et al. (2016), 'Shared values and deliberative valuation: Future directions', Ecosystem services 21, 358-371.

Kilian, Thomas, Nadine Hennigs and Sascha Langner (2012), 'Do millennials read books or blogs? introducing a media usage typology of the internet generation', Journal of Consumer Marketing $\mathbf{2 9}(2), 114-124$.

Le Hebel, Florence, Pascale Montpied, Val $\breve{A}$ Fontanieu et al. (2014), 'What can influence students' environmental attitudes? results from a study of 15-year-old students in france.', International Journal of Environmental and Science Education 9(3), 329-345.

Lomborg, Stine and Mette Mortensen (2017), 'Users across media: An introduction', Convergence 23(4), 343-351.

Mace, Georgina M, Ken Norris and Alastair H Fitter (2012), 'Biodiversity and ecosystem services: a multilayered relationship', Trends in ecology \& evolution 27(1), 19-26.

Maxwell, Sean L, Richard A Fuller, Thomas M Brooks and James EM Watson (2016), 'Biodiversity: The ravages of guns, nets and bulldozers', Nature 536(7615), 143-145. 
McCauley, Douglas J, Malin L Pinsky, Stephen R Palumbi, James A Estes, Francis H Joyce and Robert R Warner (2015), 'Marine defaunation: animal loss in the global ocean', Science $\mathbf{3 4 7}(6219), 1255641$.

McKelvey, Richard D and William Zavoina (1975), 'A statistical model for the analysis of ordinal level dependent variables', Journal of mathematical sociology 4(1), 103-120.

Muth, John F (1961), 'Rational expectations and the theory of price movements', Econometrica: Journal of the Econometric Society pp. 315-335.

OECD (2016), Programme for International Student Assessment (PISA) 2015 Database: Stduent Questionnaire data file, Organization for Economic Co-operation and Development, Paris, France. Retrieved on 30 March 2018 from.

URL: http://www.oecd.org/pisa/data/2015database/

OECD (2017), PISA 2015 Technical Report: Chapter 04 - Sample design, Organization for Economic Co-operation and Development, Paris, France. Retrieved on 30 March 2018 from.

URL: http://www.oecd.org/pisa/sitedocument/PISA-2015-technical-report-final.pdf

Ostrom, Elinor Ed, Thomas Ed Dietz, Nives Ed Dolšak, Paul C Stern, Susan Ed Stonich and Elke U Weber (2002), The drama of the commons., National Academy Press.

Oweini, Ahmad and Ahmad Houri (2006), 'Factors affecting environmental knowledge and attitudes among lebanese college students', Applied Environmental Education and Communication $5(2), 95-105$.

Pozzali, Andrea and Paolo Ferri (2012), The media diet of university students in italy: An exploratory research, in 'Current Trends and Future Practices for Digital Literacy and Competence', IGI Global, pp. 84-93.

R Core Team (2015), R: A Language and Environment for Statistical Computing, R Foundation for Statistical Computing, Vienna, Austria.

URL: https://www.R-project.org/

Ramsey, Charles E and Roy E Rickson (1976), 'Environmental knowledge and attitudes', The Journal of Environmental Education 8(1), 10-18.

Ramsfield, TD, BJ Bentz, M Faccoli, H Jactel and EG Brockerhoff (2016), 'Forest health in a changing world: effects of globalization and climate change on forest insect and pathogen impacts', Forestry 89(3), 245-252. 
Ripple, William J, Thomas M Newsome, Christopher Wolf, Rodolfo Dirzo, Kristoffer T Everatt, Mauro Galetti, Matt W Hayward, Graham IH Kerley, Taal Levi, Peter A Lindsey et al. (2015), 'Collapse of the world's largest herbivores', Science Advances 1(4), e1400103.

Rutkowski, David (2015), 'The oecd and the local: Pisa-based test for schools in the usa', Discourse: Studies in the cultural politics of education 36(5), 683-699.

Sajaia, Zurab (2008), 'Maximum likelihood estimation of a bivariate ordered probit model: implementation and monte carlo simulations', The Stata Journal 4(2), 1-18.

Sarrias, Mauricio (2016), 'Discrete choice models with random parameters in R: The Rchoice package', Journal of Statistical Software 74(10), 1-31.

Sengupta, Madhumala, Jayanti Das and Pintu Kumar Maji (2010), 'Environmental awareness and environment related behaviour of twelfth grade students in kolkata: Effects of stream and gender', Anwesa 5, 1-8.

Spykman, Nicholas J (2017), America's strategy in world politics: the United States and the balance of power, Routledge.

Tekin, Cigdem and Gulsen Gunes (2018), 'Environmental awareness in university students and the affecting factors', International Journal Of Community Medicine And Public Health 5(2), 422429.

The Guardian (2018), 'Last male northern white rhino's death highlights huge extinction crisis', International edition, Published Online, and Retrieved on 1st April 2018 at. https://www.theguardian.com/environment/2018/mar/20/last-male-northern-white-rhinosdeath-highlights-huge-extinction-crisis.

Vieweg, Sarah and Adam Hodges (2016), Surveillance \& modesty on social media: How qataris navigate modernity and maintain tradition, in 'Proceedings of the 19th ACM Conference on Computer-Supported Cooperative Work \& Social Computing', ACM, pp. 527-538.

Wiest, Julie B and Nahed Eltantawy (2012), 'Social media use among uae college students one year after the arab spring', Journal of Arab 8 Muslim Media Research 5(3), 209-226.

Young, Hillary S, Douglas J McCauley, Mauro Galetti and Rodolfo Dirzo (2016), 'Patterns, causes, and consequences of anthropocene defaunation', Annual Review of Ecology, Evolution, and Systematics 47, 333-358. 